University of Wollongong

Research Online

Faculty of Social Sciences - Papers (Archive) Faculty of Arts, Social Sciences \& Humanities

$1-1-2018$

Goal setting for weight-related behavior change in children: An exploratory study

Abigail (Abi) Fisher

University College London

Megan Hammersley

University of Wollongong,mlh965@uowmail.edu.au

Rachel A. Jones

University of Wollongong, rachelj@uow.edu.au

Philip J. Morgan

University of Newcastle, Philip.Morgan@newcastle.edu.au

Clare E. Collins

University of Newcastle

See next page for additional authors

Follow this and additional works at: https://ro.uow.edu.au/sspapers

Part of the Education Commons, and the Social and Behavioral Sciences Commons

Research Online is the open access institutional repository for the University of Wollongong. For further information contact the UOW Library: research-pubs@uow.edu.au 


\title{
Goal setting for weight-related behavior change in children: An exploratory study
}

\begin{abstract}
Background: There is an absence of studies exploring different goal-setting appraches and none which have examined the use of proxy goal-setting by parents for their children. Aim: To explore how proficient parents are in setting health behaviour goals for their children according to SMART (specific, measurable, achievable, realistic and time-framed) goal principles. A secondary aim was to examine associations between goal setting and change in health behaviors. Methods: Participants were parents and children taking part in one of two trials incorporating goal setting. Study 1 (Time2bHealthy) was an online program for parents of preschoolers $(n=36)$ and Study 2 (HIKCUPS) was a three-arm face-to-face trial examining a parent-centered dietary intervention, (Study2Diet); a child-centered physical activity intervention, (Study2PA); or combination of both (Study2Combo) (n 1/4 83). Goals were coded on five 'SMART' principles. Goals were scored 1 or 0 for each principle ( 1 indicated the principle was met and 0 , not met). The total maximum score for each goal was 5 . Mean total goal-score and means for each SMART principle were calculated. Results: Mean (and standard deviation) goal setting scores for Study 1 were 3.84 (0.61), Study2Diet 2.17 (1.33), Study2PA 3.18 (1.45) and Study2- Combo 2.24 (1.30). Goal-scores were significantly higher for Study 1 than Study $2(p<0.001)$. In Study2Diet, goal setting was significantly associated with greater reduction in energy intake $(p=0.019)$. Conclusions: Goal-scores were highest in Study 1 , which used a supported online format for setting goals. Parents were better at setting physical activity goals, but these goals did not translate into improvements in physical activity behavior. Goals set by parents may be useful in energy intake reduction, however further research is required to determine benefits for weight status or physical activity.
\end{abstract}

\section{Disciplines}

Education | Social and Behavioral Sciences

\section{Publication Details}

Fisher, A., Hammersley, M. L., Jones, R. A., Morgan, P. J., Collins, C. E. \& Okely, A. (2018). Goal setting for weight-related behavior change in children: An exploratory study. Nutrition and Health, 24 (2), 67-74.

\section{Authors}

Abigail (Abi) Fisher, Megan Hammersley, Rachel A. Jones, Philip J. Morgan, Clare E. Collins, and Anthony D. Okely 
Title: Goal setting for weight-related behavior change in children: an exploratory study 


\section{ABSTRACT}

Aim: The primary aim was to explore how proficient parents are in setting health behaviour goals for their children according to SMART goal principles. A secondary aim was to examine associations between goalsetting and change in health behaviors.

Methods: Participants were parents and children taking part in one of two trials incorporating goal-setting. Study 1 (Time2bHealthy) was an online program for parents of preschoolers $(\mathrm{n}=36)$ and Study 2 (HIKCUPS) was a three-arm face-to-face trial examining a parent-centered dietary intervention (Study2Diet), a childcentered physical activity intervention (Study2PA), or combination of both (Study2Combo) (n=83). Goals were coded on five 'SMART' principles. Goals were scored 1 or 0 for each principle ( 1 indicated the principle was met and 0 not met). The total maximum score for each goal was 5. Mean total goal-score and means for each SMART principle were calculated.

Results: Mean (SD) goal-setting scores for Study 1 were 3.84 (0.61), Study2Diet 2.17 (1.33), Study2PA 3.18 (1.45) and Study2Combo 2.24 (1.30). Goal-scores were significantly higher for Study 1 than Study 2 (p<0.001). In Study2Diet, goal-setting was significantly associated with greater reduction in energy intake $(\mathrm{p}=0.019)$.

Conclusions: Goal-scores were highest in Study 1, which used a supported online format for setting goals. Parents were better at setting physical activity goals, but these goals did not translate into improvements in physical activity behavior. Goals set by parents may be useful in energy intake reduction, however further research is required to determine benefits for weight status or physical activity.

Keywords: child health; obesity; physical activity; behavioral research; nutrition 


\section{INTRODUCTION}

Population levels of overweight and obesity are internationally high (World Health Organization, 2012). Since large proportions of children are already overweight or obese by the time they reach middle-childhood, the early years are a critical life stage for health behavior change (Dattilo et al, 2012). Successful behavior change is underpinned by behavior change theories such as Social Cognitive Theory (Bandura, 1986), a key component of which is goal setting (GS).

Four components have been identified as being important in the GS process; recognizing the need for change, setting the goal, self-monitoring and feedback/reward (Cullen et al, 2001), with planning and self-monitoring being described as particularly useful (Locke and Lathan, 2002). Intrinsic value of the goal is also thought to influence successful GS and behavior change (Sebire et al, 2009). The 'SMART' goal principle (specific, measurable, achievable, realistic and time-framed) developed by Locke and Latham (2002) has been used in a number of behavior change studies in adults with some success (Kyllo and Landers, 1995; Pearson, 2012).

GS has been a component of many health behavior change studies in adults, but there have been few studies in children and the results have been mixed (Shilts et al, 2004a). A recent review concluded that while GS is widely used in youth health behavior interventions, there is a need for research to evaluate effectiveness (Locke and Latham, 2013). A number of studies in children and adolescents have demonstrated positive outcomes in BMI z-score, physical activity (PA) and/or dietary intake GS where the children/adolescents set the goals themselves (Cullen et al, 2007; Latif et al, 2011; Shilts et al, 2009; Thompson et al, 2015; White and Skinner 1988; McDonald and Trost, 2015; Nguyen et al, 2014; Fulkerson et al, 2017). GS in these studies has taken place in varied contexts including internet-based (Latif et al, 2011), as part of a multimedia game (Cullen et al, 2007; Thompson et al, 2015) and as part of a group lesson (Shilts et al, 2009; White and Skinner, 1988).

There have been no studies (to our knowledge) which have compared the use of different GS approaches. Additionally, few studies in children have used SMART-GS and none have examined proxy-goals set by parents for their children. Given the influence of GS on behavior change and the important role of parents in setting and facilitating such goals, the primary aim of this study was to explore how proficient parents are in setting SMART behavior change goals for their children, comparing two different intervention approaches. Studies which incorporate GS differ in the type of approach used, so it is important to explore the effect of these 
different approaches. A secondary aim was to explore associations between SMART-GS and change in BMI SDS (Standard Deviation Score), weight, PA, dietary or screen-time behaviors in response to the interventions.

\section{MATERIALS AND METHODS}

Participants for this exploratory study were drawn from two studies carried out in the Universities of Wollongong and Newcastle, NSW, Australia; Time2bHealthy (Study 1) (Jones et al, 2011) and HIKCUPS (Hunter Illawarra Kids Using Parent Support) (Study 2) (Jones et al, 2007; Okely et al, 2010). These studies were selected as they both involved parents as the main agent of change and utilised SMART goal principles for parents to set 'proxy' goals for their children. The studies were conducted in different settings and used different approaches, allowing comparison of contextual effects. A description of the intervention, theoretical basis and GS context of each study is provided in Table $\mathbf{1 .}$

Study 1 was a self-directed online program for parents of preschool children (2-5 years) at risk of overweight (defined as one or more parents having a BMI of >25) (Jones et al, 2011). The intervention was 10 weeks in duration and contained 5 modules focusing on aspects of healthy-eating, PA and screen-time. The modules were completed sequentially and participants gained access to each module after the completion of the previous one. Parents were encouraged to complete one module per fortnight. At the end of each module parents were asked to create SMART-goals for the target behaviors. Participants were given online instructions on setting a SMART-goal and were provided with feedback after setting each goal and an opportunity to refine it. In the feasibility trial, 36 of the 40 parents involved (90\%) recorded goals (Jones et al, 2011).

Study 2 (HIKCUPS) was a 6-month 3-arm RCT in a group, face-to-face setting for overweight and obese children aged 5.5 to 9.9 years which compared the effectiveness of a parent-focused dietary arm (Study2Diet) a child-centered activity arm (Study2PA) or a combination of both (Study2Combo) (Jones et al, 2007; Okely et al, 2010). Parents were taught how to set SMART-goals in a group session, which included addressing barriers and recording goals on a goal chart. Goal charts were available for 91 of the 165 children (55\%). Ethical approval for both studies was given by the University of Wollongong Human Research Ethics Committee (HE08/060, HE04/289) and the University of Newcastle Ethics Committee (Health3:7/02) and parents provided informed written consent. 
Parents recorded online (Study 1) or handwritten goals (Study 2). All goals were coded by one researcher (AF) using a framework created for this study. The framework was based on the five 'SMART' principles. e.g.; specific versus non-specific goals were 'we will do activity' (non-specific; coded 0) versus 'we will play cricket' (specific; coded 1). A similar process was applied to the other constructs e.g.; measurable and timeframed goals included ‘..on a Wednesday and Friday after school for 30 minutes' (coded 1) versus '..more often ' (coded 0). A total 'SMART' score was then calculated (ranging from 0-5). A total mean goal-score, as well as means for each SMART principle, were computed.

A second rater (HG) coded $10 \%$ of goals and good to excellent intraclass correlations were achieved for total scores $(\mathrm{r}=0.85$; CI 0.78, 0.90; $\mathrm{p}<0.001)$ specific $(\mathrm{r}=0.74$; CI 0.61, 0.82; $\mathrm{p}<0.001)$ measurable $(\mathrm{r}=0.80, \mathrm{CI} ; 0.71$, $0.87 ; \mathrm{p}<0.001)$ achievable $(\mathrm{r}=0.81 ; \mathrm{CI} 0.72,0.87 ; \mathrm{p}<0.001)$ realistic $(\mathrm{r}=0.85 ;$ CI $0.78,0.89 ; \mathrm{p}<0.001)$ and timeframed (r=0.78; CI 0.68, 0.85; p<0.001). In HIKCUPS 493 goals (56\% PA, $40 \%$ dietary and 4\% mixed) and in Time2bHealthy 314 goals (48\% PA/sedentary time-focused and 52\% dietary) were included. Sedentary time goals were sometimes embedded in dietary goals (e.g. 'switch the TV off at mealtimes'; coded as diet) and PA goals (e.g. 'watch 1 hour less TV in the afternoon Wed and Fri and play outside instead'; coded as PA). Since goals targeting purely sedentary time were rare, these were included with PA goals. Four percent of goals were 'mixed' diet and PA that could not be clearly categorized as one or the other (e.g. 'we're going to eat healthily and exercise more Tuesdays and Thursdays').

Height, weight and waist circumference were measured by trained researchers at baseline and 3 months (Study 1) and baseline and 6 months (Study 2) using standard procedures (Cole et al, 1998). BMI was calculated and converted to age-and-sex adjusted BMI SDS (NHS National Obesity Observatory, 2011).

In study 1, children's PA and dietary behaviors were recorded by parents using questions on dietary intake, activity and screen-time (developed for this study and based on questionnaires previously tested for reliability) (Campbell et al, 2013; Hinkley et al, 2012). The questions included from Study 1 to most closely match the variables available in Study 2 were 'My child eats vegetables / fruit daily' (Fruit \& Veg), 'My child eats chocolate or lollies (sweets)/potato chips or salty snacks...' (non-core snacks) and for PA behavior, 6 questions including 'My child does PA regularly' and 'I participate in activity with my child...' Minutes of weekday and 
weekend TV-time were also reported and total TV-time calculated. Outcomes were assessed at baseline and at 3 months.

In Study 2 parents completed a validated 137-item Food Frequency Questionnaire (Watson et al, 2003). Energy intake was reported as kilojoules per kilogram to standardize for body mass. Children's activity was measured over eight days using the Actigraph 7164 accelerometer. Data were collected in 1-minute epochs and mean counts per minute used as a measure of PA. Children were considered to have valid data if they had worn the monitor for at least 600 minutes per day on at least 4 days. Previous PA studies in children indicate that activity can vary throughout the day, therefore this minimum threshold was used to obtain an accurate representation of activity over the day (Trost et al, 2000). Activity count thresholds were applied to determine the amount of time spent in moderate to vigorous-intensity physical activity (MVPA) (MVPA threshold $\geq 3.0$ METs; from 6 years $\geq 614$ counts through to 10 years $\geq 1017$ counts) (Cliff et al, 2011). Outcomes were assessed at baseline and 6 months.

Participant characteristics between Studies 1 and 2 were compared using $t$ tests. Comparisons of SMART-scores between studies were carried out using analysis of variance (ANOVA). Comparison of dietary and PA goalscores were carried out using ANCOVA, adjusting for study, child age and sex. Associations between BMI SDS and GS and behavioral outcomes and GS were examined using linear regression adjusting for the baseline measure of BMI SDS, energy intake and PA, child age and sex. Analyses were carried out in SPSS Version 18 and alpha set at $\mathrm{p}<0.05$.

\section{RESULTS}

Participant characteristics are shown in Table 2. Participants in Study 1 were younger (as this study targeted preschool children) and had lower BMI SDS than children in Study 2 (which targeted school-aged children).

\section{Goal-setting: can parents set SMART-goals?}

Parents provided around 8 goals each. Goal-scores are shown in Figure 1. Totals ranged from a mean of 2.2 (SD 1.3) in Study2Combo to 3.8 (SD 0.6) (from a possible 5) in Study 1. In Study 1, where guided online goals were set, parents were reasonably good at all aspects of GS except time-framing (scoring $\geq 0.8$ out of 1 for all aspects except time-framed (0.4)). In all arms of Study 2, where parents set goals in a group setting, parents 
performed best at setting achievable (0.6-0.7) and realistic goals (0.6-0.7), but scores were lower for specific (0.5-0.7) and measurable (0.3-0.7) aspects and lowest for time-framing (0.1-0.4). Overall, parents were significantly better at setting PA goals and sedentary time goals than diet-related goals. When considering the type of goal set, the mean goal-score for Study 1 for diet was 3.20 (SD 1.26) for PA was 4.54 (SD 0.72). The mean goal-score diet for Study 2 was 2.39 (SD 1.44) and for PA was 2.56 (SD 1.70). Parents participating in Study 1 had significantly higher GS scores than parents in Study 2 ( $\mathrm{p}<0.001$, mean difference 1.15, 95\% confidence interval 1.00, 1.91).

Simple associations between change in BMI SDS and SMART goal-scores are presented in Table 3. There were no significant associations between change in BMI SDS and total goal-score in any study. Similarly, there were no significant associations between any of the SMART components and weight change.

In Study2Diet, decrease in energy intake was associated with goal-score. For each additional unit of total goalscore, energy intake was around $18.04 \mathrm{~kJ}-\mathrm{kg} / \mathrm{d}$ lower (95\% CI -2.58, -33.51, $\mathrm{p}=0.024)$. Sub-analyses suggested that specific $(-88.07 \mathrm{~kJ}-\mathrm{kg}, 95 \% \mathrm{CI}-141.50,-34.65, \mathrm{p}=0.003)$ measurable $(-76.93 \mathrm{~kJ}-\mathrm{kg}, 95 \% \mathrm{CI}-140.57,-$ 13.92, $\mathrm{p}=0.02)$ and time-framed $(-4.94 \mathrm{~kJ}-\mathrm{kg}, 95 \% \mathrm{CI}-162.92,-6.97, \mathrm{p}=0.03)$ dietary goals were significantly associated with lower energy intake. Achievable and realistic scores were not significantly associated with energy intake (both $\mathrm{p}=0.361$ ). There were no significant associations between GS and either PA or screen-time

(Table 3).

\section{DISCUSSION}

To our knowledge, this is the first study to report 'proxy'-GS by parents for their children and the first to compare two different approaches to setting goals, addressing a significant gap in the literature on GS in health behavior change interventions for children. For parents of young children participating in a weight management intervention, an online format with training and feedback resulted in higher SMART goal scores, compared to a face-to-face group-based approach with less SMART goal training. The differences in SMART-GS may have been influenced by a number of factors. For example, there is evidence that where self-assessment precedes GS, there is likely to be a greater commitment and perhaps even better process and quality of GS (Locke and Latham, 2002). In Study 1 parents were asked first to complete a weekly planner reporting current behavior. Although the extent of self-assessment in study 1 was not measured, it is likely that the weekly planner activity 
facilitated the identification of a need for change and may have encouraged planning and self-monitoring both of which are important steps in successful GS (Locke et al, 1980).

In Study 1, goals were self-determined (or proxy-determined) but guided and supported online, whereas in Study 2 they were collaborative (i.e. determined in a group setting). In 13 studies in adults that compared the nature of GS, those using self-determined GS generally reported greater weight change (Shilts et al, 2004a). This is supported by the fact that intrinsic value of the goal is a significant predictor of GS and subsequent behavior change in adults (Sebire et al, 2009). The nature of the online format in Study 1 meant that GS was to some extent more guided as each component of the SMART-goal was outlined for the participants. Guided GS has been proposed as an alternative to intensive collaborative GS. Shilts et al (2004b) developed an innovative online guided GS system for adolescents, where an algorithm generates areas where improvement is required, participants then select an area and a SMART-goal is generated (Shilts et al, 2004b). This system allows both guidance and selection so that participants feel some autonomy and choose goals of intrinsic value. Whilst the Shilts et al (2004b) study was designed for adolescents, our results in alignment with their results suggest that a guided format may also be better for parents.

We found that in Study2Combo, where dietary intake and PA were addressed, there was no significant association between GS and behavior change. In a study examining weight-loss in 132 female university students, reported weight-loss was greater in those who focused on either PA or dietary goals, rather than combined goals (Knauper et al, 2005). Weight reduction was greatest in those who focused on a 'reducing calorie' goal (Knauper et al, 2005). It may be possible that parents, when setting 'proxy' goals for their children, are less likely to be successful when more than one area of behavior change is focused on at a time. Further research is needed to investigate this.

We found a significant association between goal quality and change in energy intake in response to a dietary intervention; those parents who had higher goal-scores reported significantly greater reductions in their children's energy intake from baseline to 6-month follow-up. GS has been shown to enhance the effects of adult nutrition programs (Cullen et al, 2001), but few studies in children have reported GS specifically in relation to children's dietary behavior change and results are mixed. In 473 10-14 year old boys involved in a two-arm trial aimed at increasing vegetables and fruit juice or increasing activity, internet-based GS and goal attainment were 
not associated with change (Latif et al, 2011). GS were associated with greater increase in consumption if availability was high, but if availability was low, intake decreased (Latif et al, 2011). In another study, attainment of fruit-juice or vegetable goals recorded online by children was associated with an increase in corresponding fruit-juice or vegetable intake in response to intervention, but again, other factors (such as food preference and baseline consumption) mediated this relationship (Cullen et al, 2004). Another study of childparent dyads found that GS when accompanied by action-planning in relation to fruit and vegetable intake resulted in a significant increase in fruit and vegetable intake (Thompson et al, 2015). Finally, a more recent study which involved GS phone calls resulted in significant improvements to parent self-efficacy in regard to portion sizes for parents of 8-12 year olds and significant reduction in consumption of sugar sweetened beverages by the child participants (Fulkerson et al, 2017). Overall, most results indicate that GS enhances dietary changes, aligning with our study findings.

When considering the components of SMART dietary goals, we found the specific, measurable and time-framed aspects to be the most important. There was a significant association between higher goal-scores for these aspects and reduction in energy intake. There was no significant association between the achievable and realistic aspects and energy intake. This finding complements recent evidence relating to weight goals in adults, which indicates that setting realistic and achievable goals may not be a factor for success and that setting more challenging goals is not detrimental and may indeed result in superior outcomes (Casazza et al, 2013).

In the current study there was no association between GS and PA behavior. Despite there being an association between GS and sporting performance in the literature (Michie et al, 2009), few studies have focused on childhood. Three studies which have investigated the effects of GS on PA in children and adolescents have reported significant changes in PA outcomes including aerobic fitness (McDonald and Trost, 2015) and steps ((Horne et al, 2009; Lubans et al, 2009). However, two studies have reported contrasting results. Latif et al (2011) and Shilts et al (2009)found no effect of PA. Despite being statistically non-significant (perhaps due to small sample sizes) in both Study 1 and Study2PA, there were large reductions in screen-time (of more 70 minutes per week per unit of GS). Given this trend, it would be worth considering targeting screen-time in future studies. Also, 'pure' sedentary time goals were limited (and therefore combined with dietary of PA goals), so effects may have been diluted. 
Some limitations need to be considered. First, there was a difference in the age of the child participants between the two studies. Study 1 involved preschool-aged children and study 2 involved school-aged children. However, it was the parent that was responsible for setting and implementing goals in both studies. The ease by which parents set goals for their children may have differed on the basis of their age and may have been a factor in the differences in goal-scores. There was also a difference in the duration of the two studies (10 weeks and 6 months), although both were an appropriate length to detect behavior change (McDonald and Trost 2015; Cullen et al, 2004). Validated questionnaires were not used in Study 1 due to the unavailability of appropriate validated measures at the time the study was conducted. Questions were designed for the study and where possible, measures which had been tested for reliability were used as a basis (Campbell et al, 2013; Hinkley et al, 2012). Finally, the size of the sample for these studies was relatively small compared to some similar studies (Cullen et al, 2007; Latif et al, 2011; Thompson et al, 2015), but justified given the exploratory nature of the study.

This exploratory study was the first to address the ability of parents to set goals for their children and one of few to examine explicitly whether goals were related to behavior change in response to intervention. It is also the first study to compare different approaches to GS. We found that parents who used a guided online selfdetermined SMART-GS format, where instructions and individual feedback was provided, achieved higher goal scores than parents who used a group-based SMART-GS approach where less feedback was provided. Overall, parents were better at setting PA than dietary goals, yet it was dietary goals that were significantly associated with greater reduction in energy intake in one study arm. The findings of this study therefore suggest that 'proxy'-GS by parents is useful to attain health behavior change in their children. The GS approach that is used to support parents in developing goals may also be important. Further research is required to investigate the efficacy of weight status and PA 'proxy'-GS. 


\section{REFERENCES}

Bandura A (1986). Social Foundations of Thought and Action: A Social Cognitive Theory. Englewood Cliffs, NJ: Prentice Hall.

Bellamy R (2004). An introduction to patient education: theory and practice. Medical Teacher 26:359-365.

Campbell KJ, Lioret S, McNaughton SA, Crawford DA, Salmon J, Ball K, McCallum Z, Gerner BE, Spece, AC, Cameron AJ, Hnatiuk JA, Ukoumunne OC, Gold L, Abbott G, Hesketh KD (2013). A parent-focused intervention to reduce infant obesity risk behaviors: a randomized trial. Pediatrics 131:652-660.

Casazza K, Fontaine KR, Astrup A, Birch LL, Brown AW, Bohan Brown MM, Durant N, Dutton G, Forster EM, Heymsfield SB, McIver K, Mehta T, Menachemi N, Newby PK, Pate R, Rolls BJ, Sen B, Smith DL, Thomas DM and Allison DB (2013). Myths, presumptions and facts about obesity. New England Journal of Medicine: 368:446-454.

Cliff DP, Okely AD, Morgan PJ, Steele JR, Jones RA, Colyvas K and Baur LA (2011). Movement Skills and Physical Activity in Obese Children: Randomized Controlled Trial. Medicine and Science in Sports and Exercise 43: 90-100.

Cole TJ, Freedman JV and Preece MA (1998). British 1990 growth reference centiles for weight, height, body mass index and head circumference fitted by maximum penalized likelihood. Statistics in Medicine 28, 407-429.

Cullen KW, Baranowski T and Smith SP (2001). Using goal setting as a strategy for dietary behavior change. Journal of the American Dietetic Association 101:562-566.

Cullen KW, Watson KB, Zakeri I, Baranowski T and Baranowski J (2007). Achieving fruit, juice, and vegetable recipe preparation goals influences consumption by $4^{\text {th }}$ grade students. International Journal of Behavioral Nutrition and Physical Activity 4:28-34. 
Cullen KW, Zakeri I, Pryor EW, Baranowski T, Baranowski J and Watson K (2004). Goal setting is differentially related to change in fruit juice and vegetable consumption among fourth gradechildren. Health Education and Behavior 31:258-269.

Dattilo AM, Birch L, Krebs NF, Lake L, Taveras EM and Saavedra JM (2012). Need for early interventions in the prevention of pediatric overweight: a review and upcoming directions. Journal of Obesity: Epub May 17. http://dx.doi.org/10.1155/2012/123023.

Fulkerson JA, Friend S, Horning M, Flattum C, Draxten M, Neumark-Sztainer D, Gurvich O, Garwick A, Story M and Kubik MY (2017). Family home food environment and nutrition-related parent and child personal and bahevioral outcomes of the healthy home offerings via the mealtime environment (HOME) plus program: a randomized controlled trial. Journal of the Academy of Nutrition and Dietetics article in press. doi: 10.1016/j.jand.2017.04.006.

Harter S (1978). Effectance motivation reconsidered: toward a developmental model. Human Development 21:34-64.

Hinkley T, Salmon J, Okely AD, Crawford D, Hesketh K (2012). The HAPPY study: development and reliability of a parent survey to assess corrrelates of preschool children's physical activity. Journal of Science and Medicine in Sport 15:407-417.

Horne PJ, Hardman CA, Lowe CF and Rowlands AV (2009). Increasing children's physical activity: a peer modelling, rewards and pedometer-based intervention. European Journal of Clinical Nutrition 63:191-198.

Jones RA, Okely A, Collins C, Morgan PJ, Steele JR, Warren JM, Baur LA, Cliff DP, Burrows T, Cleary J (2007). The HIKCUPS trial: a multi-site randomized controlled trial of a combined physical activity skill-development and dietary modification programme in overweight and obese children. BMC Public Health 7.

Jones R, Wells M, Okely A, Lockyer L and Walton K (2011). Is an online healthy lifestyles programme acceptable for parents of preschool children? Nutrition and Dietetics 68:149-154. 
Knauper B, Cheema S, Rabiau M and Borton O (2005). Self-set dieting rules: adherence and prediction of weight loss success. Appetite: 44:283-288.

Kyllo LB and Landers DM (1995). Goal setting in sport and exercise: a research synthesis to resolve the controversy. Journal of Sport and Exercise Psychology: 17: 117-137.

Latif H, Watson K, Nguyen N, Thompson D, Baranowski J, Jago R, Cullen KW and Baranowski T (2011). Effects of goal setting on diet and physical activity in the Boy Scout Badges projects. Health Education and Behavior 38:521-529.

Locke EA and Latham GP (2002). Building a practically useful theory of goal setting and task motivation. A 35year odyssey. American Psychologist 57:705-717.

Locke EA, Latham GP (2013). New developments in goal setting and task performance. NY:Routledge.

Locke EA, Shaw KN, Saari LM and Latham GP (1980). Goal-setting and task performance: 1969-1980. Psychological Bulletin 90:125-152.

Lubans DR, Morgan PJ, Callister R and Collins CE (2009). Effects of integrating pedometers, parental materials and email support within an exctracurricular school sport intervention. Journal of Adolescent Health 44:176-183.

Michie S, Abraham C, Whittington C, McAteer J, Gupta S (2009). Effective techniques in healthy eating and physical actvity interventions: a meta-regression. Health Psychology 28:690-701.

McDonald SM and Trost SG (2015). The effects of a goal setting intervention on aerobic fitness in middle school students. Journal of Teaching in Physical Education 34:576-587.

Nguyen B, Shrewberry VA, O'Connor J, Lau C, Steinbeck KS, Hill AJ and Baur LA (2014). A process evaluation of an adolescent weight management intervention: findings and recommendations. Health Promotion International 30:201-212.

Nixon CA, Moore HJ, Douthwaite W, Gibson EL, Vogele C, Kreichauf S, Wildgruber A, Manios Y and Summerbell CD (2012). ToyBox-study group. Identifying effective behavioral models and 
behavior change strategies underpinning preschool- and school-based obesity preventions aimed at 3-6 year olds: a systematic review. Obesity Reviews 13:106-117.

NHS National Obesity Observatory (2011). A Simple Guide to Classifying Body Mass Index in Children. England: NHS.

Okely AD, Collins CE, Morgan PJ, Jones RA, Warren JM, Cliff DP, Burrows TL, Colyvas K, Steele JR and Baur L (2010). Multi-site randomized controlled trial of a child-centered physical activity program, a parent-centered dietary-modification program, or both in overweight children: the HIKCUPS study. Journal of Pediatrics 157:388-394.

Pearson ES (2012). Goal setting as a health behavior change strategy in overweight and obese adults: a systematic review examining intervention components. Patient Education and Counselling $87: 32-42$.

Sebire SJ, Standage M and Vansteenkiste M (2009). Examining instrinsic versus extrinsic exercise goals: cognitive, affective and behavioral outcomes. Journal of Sport and Exercise Psychology 31:189-210.

Shilts MK, Horowitz M and Townsend MS (2004a). Goal setting as a strategy for dietary and physical activity behavior change: a review of the literature. American Journal of Health Promotion 19:81-93.

Shilts MK, Horowitz M and Townsend MS (2004b). An innovative approach to goal setting for adolescents: guided goal setting. Journal of Nutrition Education and Behavior 36:155-156.

Shilts MK, Horowitz M and Townsend MS (2009). Guided goal setting: effectivness in a dietary and physical activity intervention with low-income adolescents. International Journal of Adolescent Medicine and Health 21:111-112.

Thompson D, Bhatt R, Vazquez I, Baranowski J, Baranowski T and Liu, Y (2015). Creating action plans in a serious video game increases and maintains child fruit-vegetable intake: a randomized controlled trial. International Journal of Behavioral Nutrition and Physical Activity 12:39-48.

Trost SG, Pate RR, Freedson PS, Sallis JF and Taylor WC (2000). Using objective physical activity measures with youth: how many days of monitoring are needed? Med Sci Sports Exerc 32: 426-431. 
Watson JF, Collins CE, Dibley MJ, Garg M and Sibbritt D (2003). Design considerations in the development of a food-frequency questionnaire for school-aged children. Asia Pacific Journal of Clinical Nutrition 12:S24.

White AA and Skinner JD (1988). Can goal setting as a component of nutrition education effect behavior change among adolescents? Journal of Nutrition Education and Behavior 6:327-335.

World Health Organization. Population-based Approaches to Childhood Obesity Prevention. Resource document. World Health Organisation 2012. http://apps.who.int/iris/bitstream/10665/80149/1/9789241504782_eng.pdf. Accessed 8 August 2017. 


\begin{tabular}{|c|c|c|c|c|c|c|c|}
\hline & Description & Theoretical basis & Length & Description of GS & Focus on GS & $\begin{array}{l}\text { Target } \\
\text { behavior }\end{array}$ & Context of GS \\
\hline Study 1 & $\begin{array}{l}\text { Parent-centered online } \\
\text { program, one module every } \\
2 \text { weeks [intro, diet, } \\
\text { snacking, PA, screen time]. }\end{array}$ & $\begin{array}{l}\text { Social Cognitive } \\
\text { Theory }^{\mathrm{a}}\end{array}$ & 10 weeks & $\begin{array}{l}\text { Parents asked to } \\
\text { consider SMART goals } \\
\text { for each behavior, given } \\
\text { examples, prompted to } \\
\text { choose what and when } \\
\text { they would implement }\end{array}$ & $\begin{array}{l}\text { Emphasized } \\
\text { strongly } \\
\text { throughout, } \\
\text { recorded }\end{array}$ & $\begin{array}{l}\text { Diet, PA, } \\
\text { screen/ } \\
\text { sedentary } \\
\text { time }\end{array}$ & $\begin{array}{l}\text { Weekly planner for target } \\
\text { behavior. Goals for target } \\
\text { behavior recorded online at } \\
\text { end of module. Individual } \\
\text { feedback on SMART goals } \\
\text { provided and participants then } \\
\text { asked to refine goals }\end{array}$ \\
\hline Study 2Diet & $\begin{array}{l}\text { Parent-centered dietary } \\
\text { modification } \\
\text { Parent group sessions - } \\
\text { reduce energy intake, } \\
\text { increase fruit and } \\
\text { vegetables, healthy snacks } \\
\text { and drinks }\end{array}$ & $\begin{array}{l}\text { Health Belief Model }{ }^{\text {b }} \\
\text { [Small daily changes, } \\
\text { GS, problem solving, } \\
\text { role modeling, +ve } \\
\text { reinforcement] }\end{array}$ & $\begin{array}{l}6 \text { months } \\
{[10 \times 2 \mathrm{hr} \text { weekly sessions }} \\
\text { followed by } 3 \text { months } \\
\text { monthly phone calls] }\end{array}$ & $\begin{array}{l}\text { Parents educated on } \\
\text { SMART principles then } \\
\text { asked to set goals and } \\
\text { implement. GS was in } \\
\text { the } 3 \text { month follow-up. }\end{array}$ & $\begin{array}{l}\text { Throughout } \\
\text { (recorded only } \\
\text { after } 10 \text { weeks) }\end{array}$ & Diet & $\begin{array}{l}\text { Goals recorded by parents in } \\
\text { week } 10 \text { on charts. No } \\
\text { individual feedback provided } \\
\text { on SMART goals. Monthly } \\
\text { calls for next } 3 \text { months to } \\
\text { discuss goal progress. }\end{array}$ \\
\hline Study2PA & $\begin{array}{l}\text { Child centered PA and skill } \\
\text { development program } \\
\text { Child group FMS sessions } ~ \\
\text { Home Challenge Folder for } \\
\text { practice with family } \\
2 \times 1 \text { hour session for } \\
\text { parents and } 2 \text { hour refresher } \\
\text { after } 2 \text { months }\end{array}$ & $\begin{array}{l}\text { Competence } \\
\text { Motivation Theory } \\
\text { [children's motivation }^{\text {for PA influenced by }} \\
\text { physical competence, } \\
\text { social support and } \\
\text { enjoyment] }\end{array}$ & $\begin{array}{l}6 \text { months } \\
\text { [10 x } 2 \mathrm{hr} \text { weekly sessions } \\
\text { followed by } 3 \text { months } \\
\text { monthly phone calls] }\end{array}$ & $\begin{array}{l}\text { Parents attend a } 1 \text { hour } \\
\text { workshop on SMART } \\
\text { goals }\end{array}$ & After 10 weeks & $\begin{array}{l}\text { PA, sedentary } \\
\text { time }\end{array}$ & $\begin{array}{l}\text { Goals recorded by parents in } \\
\text { week } 10 \text { on charts. Monthly } \\
\text { calls for next } 3 \text { months to } \\
\text { discuss goal progress. No } \\
\text { individual feedback provided } \\
\text { on SMART goals. }\end{array}$ \\
\hline $\begin{array}{l}\text { Study } \\
\text { 2Combo }\end{array}$ & $\begin{array}{l}\text { Combination of both } \\
\text { Study2Diet and Study2PA }\end{array}$ & $\begin{array}{l}\text { Health Belief Model } \\
\text { and Competence } \\
\text { Motivation Theory }\end{array}$ & $\begin{array}{l}6 \text { months } \\
\text { [10x } 2 \mathrm{hr} \text { weekly sessions } \\
\text { followed by } 3 \text { months } \\
\text { monthly phone calls] }\end{array}$ & $\begin{array}{l}\text { Combination of both } \\
\text { Study2Diet and } \\
\text { Study2PA }\end{array}$ & $\begin{array}{l}\text { Throughout and } \\
\text { after } 10 \text { weeks }\end{array}$ & $\begin{array}{l}\text { Diet, PA, } \\
\text { sedentary } \\
\text { time }\end{array}$ & $\begin{array}{l}\text { Combination of both } \\
\text { Study2Diet and Study2PA }\end{array}$ \\
\hline
\end{tabular}


Table 2. Participant characteristics

\begin{tabular}{|c|c|c|c|}
\hline Study 1 & Study 2PA & Study 2Diet & Study 2Combo \\
\hline$n=36$ & $\mathrm{n}=18$ & $n=25$ & $n=40$ \\
\hline $3.1(0.8)$ & $8.0(1.2)$ & $8.5(1.2)$ & $8.1(1.2)$ \\
\hline $64 / 36$ & $44 / 56$ & $39 / 61$ & $46 / 54$ \\
\hline $0.7(1.1)$ & $2.9(0.7)$ & $2.6(0.6)$ & $2.7(0.7)$ \\
\hline $0.6(0.9)$ & $2.7(0.8)$ & $2.3(0.7)$ & $2.4(0.8)$ \\
\hline- & $676(216)$ & 694 (170) & $712(123)$ \\
\hline- & $639(178)$ & $698(160)$ & 752 (166) \\
\hline - & 274 (97) & $263(92)$ & $271(141)$ \\
\hline - & $230(84)$ & $236(82)$ & 234 (97) \\
\hline
\end{tabular}

Values are means (and standard deviations) unless otherwise stated. Physical activity is mean accelerometer counts per minute. Energy intake from food frequency questionnaire converted to kilojoules $/ \mathrm{kg} / \mathrm{day}$. BL= baseline $\mathrm{FU}=$ follow-up. 
Table 3. Associations between SMART goal-score, weight status and related health behaviors

\begin{tabular}{|c|c|c|c|c|c|}
\hline \multirow[b]{3}{*}{ Study 1} & \multicolumn{5}{|c|}{ Adjusted B (95\% CI) } \\
\hline & BMI SDS & $\begin{array}{l}\text { Dietary behaviors } \\
\text { or energy intake }\end{array}$ & PA behavior & \% time MVPA & Screen-time \\
\hline & $-0.07(-0.58,0.74)$ & $\begin{array}{l}\mathrm{F} \& \mathrm{~V}: \quad 0.01(-0.08,0.17) \\
\text { NonCore: } 0.12(-0.51,0.75)\end{array}$ & $0.01(-0.19,0.22)$ & $\mathrm{nm}$ & $-83.53(-212.17,45.11)$ \\
\hline Study 2Diet & $0.02(-0.06,0.10)$ & $-18.04(-33.51,-2.58)^{*}$ & $-21.70(-73.34,29.91)$ & $-0.18(-1.93,1.56)$ & $-6.01(-106.58,94.56)$ \\
\hline Study 2PA & $-0.03(-0.09,0.04)$ & $8.10(-11.63,27.84)$ & $5.30(-90.23,100.80)$ & $-0.59(-0.65,1.82)$ & $-27.03(-139.74,85.68)$ \\
\hline Study 2Combo & $0.04(-0.03,0.10)$ & $-2.70(-22.59,17.18)$ & $36.42(-8.11,80.95)$ & $0.94(-0.73,2.62)$ & $23.81(-53.67,101.29)$ \\
\hline
\end{tabular}

Adjusted beta values from linear regression models with follow-up behavior as dependent variable, adjusting for baseline value. Study 1 Time2bHealthy online intervention, Study 2 Diet HIKCUPS dietary intervention, Study 2PA HIKCUPS physical activity intervention, Study 2Combo HIKCUPS combined diet and physical activity intervention. F\&V=fruit and vegetable intake; NonCore=snack intake; $\mathrm{nm}=$ not measured. $* \mathrm{p}<0.05$ 